\title{
The influence of polypropylene- and polyethylene microplastics on the quality of Spirulina sp. harvests
}

\author{
${ }^{1,{ }^{*}}$ Dianratri, I., ${ }^{1,2}$ Hadiyanto, H., ${ }^{1}$ Khoironi, A. and ${ }^{1}$ Pratiwi, W.Z. \\ ${ }^{1}$ Center of Biomass and Renewable Energy, Chemical Engineering Department, Diponegoro University, \\ Semarang, Java, Indonesia \\ ${ }^{2}$ Master Program of Environmental Sciences, School of Postgraduate Studies, Diponegoro University, \\ Semarang, Java, Indonesia
}

\section{Article history:}

Received: 11 April 2020

Received in revised form: 17

May 2020

Accepted: 31 May 2020

Available Online: 28 June 2020

\section{Keywords:}

Microplastics,

Polyethylene,

Polypropylene,

Spirulina sp.

DOI:

https://doi.org/10.26656/fr.2017.4(5).157

\begin{abstract}
Microplastics are polymer-based materials that require a variety of organic and inorganic chemical additives during the manufacturing process. These chemicals have an impact on aquatic organisms. This study aimed to quantify the impact of microplastics on the growth and quality of microalgae Spirulina sp. We studied the interaction between Spirulina sp. and $500 \mathrm{mg}$ of polyethylene (PE) and polypropylene (PP) microplastics. Three glass bioreactors containing $2 \mathrm{~L}$ of Spirulina sp. were observed for 30 days. The first bioreactor was untreated and acted as a control. The second was treated with PE microplastic of $1 \mathrm{~mm}$ in size, and the third was treated with similarly sized PP microplastics. Each day, the optical density (OD) was measured to determine the rate of growth of the Spirulina sp. After harvesting, the Spirulina sp. biomass was dried in an oven at $30-35^{\circ} \mathrm{C}$ for $24 \mathrm{hrs}$ and subsequently analyzed using Fourier transform infrared spectroscopy (FTIR). With PE treatment, the results showed a change in the organic structure on Spirulina sp., as well as a decline of polysaccharides and the loss of one peak at wave number $875.45 \mathrm{~cm}^{-1}$. Meanwhile, in Spirulina sp. with PP treatment, two peaks that showed polysaccharides at wavelengths of $875.45 \mathrm{~cm}^{-1}$ and $1,245.67 \mathrm{~cm}^{-1}$ were lost. The results also indicated that microplastics had a significant impact on the growth and the quality of Spirulina sp., especially in decreased polysaccharide content.
\end{abstract}

\section{Introduction}

Microplastics are small $(<5 \mathrm{~mm})$ particles formed from organic polymers. They have a profound influence on freshwater and marine ecosystems as they get ingested and do not get caught in planktonic nets (Setälä et al., 2014). Microplastics also influence higher trophic levels (Farrell and Nelson, 2013; Van Cauwenberghe and Janssen, 2014; Besseling et al., 2015) and show toxicity and increased mortality in marine plankton (Bergami et al., 2017). Several studies on the toxicity of microplastics of various sizes and characteristics show how aquatic ecosystems, including algae, ciliate, invertebrates, crustaceans, and fish (Bergami et al., 2017)

Saturated polymers, or polyolefins, have a broad range of applications, packaging being one of them. Several broad classes of plastics that are used in packaging are PE, PP, polystyrene, Polyethylene terephthalate, and Polyvinyl chloride (Andrady, 2011).
However, $\mathrm{PE}$ and $\mathrm{PP}$ (also known as $\mathrm{CnH} 2 \mathrm{n}$ ), are most commonly used. They share similar polymer characteristics, namely in polyolefin groups with linear carbon chains. PE and PP are also the most widely used linear hydrocarbon polymers (Arutchelvi et al., 2008). As a thermoplastic polymer resin with a semi-crystalline structure, PP is used in the production of packaging for mineral water, bottle caps, drinking straws, yogurt containers, and more. PE, on the other hand, is made into a soft, transparent, and flexible film that has good impact and tearing resistance and is therefore commonly used as plastic bags. They are both high molecular weight elements however that cannot be biodegraded (Lagarde et al., 2016). More specifically, plasticizer content such as phthalate, nonylphenol, and bisphenol A found in microplastics can harm aquatic microorganisms (Campanale et al., 2020). One such microorganism is the microalga Spirulina sp., often used in the food, cosmetics, and medicine industry.

Spirulina sp. can produce exopolymer substances 
(EPS), viscous gel-like structures that are speciesspecific. These are long-chain polysaccharides that are composed of repeating units of sugar derivatives with a structural diversity arisen from a broad range of noncarbohydrate substituents and linkage types (Bazaka et al., 2011). Production of EPS from microalgae such as Spirulina sp. can be encouraged by providing adequate nutrients, substrates, and oxygen during cultivation. On Spirulina sp., EPS act antibacterial, anticoagulant, antioxidative, anticancer, and anti-inflammatory (Chentir et al., 2017). As a photosynthetic microorganism, the Spirulina sp. utilizes several carbon sources. It uses $\mathrm{CO} 2$ as a carbon source to form biomass (Khoironi et al., 2019). Additionally, Gu (2003) explained that EPS from microalgae are able to break polymer bonds to produce shorter rings by utilizing microplastics to become carbon sources. Finally, Rummel et al. (2017) reported similarly by stating that plastic can be used by microalgae as a carbon source, and the release of additives in plastics can increase the growth of microorganisms by acting as carbon sources. EPS also plays a role in the biodegradation process, where it is used by microbes as a growth medium and forms heteroaggregation involving plastics, microbes and detritus (Long et al., 2015; Khoironi et al., 2019). Sjollema et al. (2016) also reported on the impact microplastics can have on the growth of microalgae and showed that microalgae absorbed microplastics so as to inhibit their own growth.

Spirulina sp. has organic functional groups in the form of polysaccharides, amides, lipids, proteins, carboxyl groups, alkyl and other useful compounds such as antioxidant (Costa et al., 2019). These are important components of Spirulina sp. These organic functional groups contained in Spirulina sp. can be an indicator of the quality of the biomass of Spirulina sp. Dmytryk et al. (2014) did an FTIR analysis to identify organic functional groups in Spirulina sp. They reported that peaks for polysaccharides appeared at wavelengths of $861.48 \mathrm{~cm}^{-1}$; for $\gamma \mathrm{CC} / \mathrm{CO}, \gamma \mathrm{OH}$ at $1,049.44 \mathrm{~cm}^{-1}$; for ether polysaccharides and polysaccharides at $1,150.86 \mathrm{~cm}^{-1}$; for amides, polysaccharides, and esters at $1,241.96 \mathrm{~cm}^{-1}$; for the carboxyl group at $1,400.08 \mathrm{~cm}^{-1}$; for alkyl rings at $1,454.64 \mathrm{~cm}^{-1}$; for the second amide at $1,541.50 \mathrm{~cm}^{-1}$; for the first amide protein at $1,654.16 \mathrm{~cm}$ 1, for alkyl chopped at $2,874.17 \mathrm{~cm}^{-1}, 2,917.79 \mathrm{~cm}^{-1}$, and $2,960.11 \mathrm{~cm}^{-1}$; and for amines at $3,302.49 \mathrm{~cm}^{-1}$. This study aimed to determine the impact PE and PP microplastics have on the growth of Spirulina sp. and the quality of Spirulina sp. biomass.

\section{Materials and methods}

Spirulina sp. was cultivated, treated with microplastics and analyzed. During the cultivation of
Spirulina sp., Each day, the content's OD was measured to determine the rate of growth of the Spirulina sp. The following variables were used: Spirulina sp. without microplastic treatment (control) (variable 1), Spirulina sp. with PE treatment (variable 2), and Spirulina sp. with PP treatment (variable 3 ).

\subsection{Preparation of Spirulina sp.}

Microalgae Spirulina sp. seeds were obtained from Neoalgae, Sukoharjo, Central Java. Microalgae cultivation, testing, and result analysis were carried out at UPT C-BIORE Laboratory, Diponegoro University, Semarang. Three glass bioreactors for all three variables were filled with 2 L of Spirulina sp., each glass equipped with an aerator for oxygen supply and each illuminated by conventional LEDs. The OD was then measured at 0.42 for all three variables. For 30 days, the $\mathrm{pH}$ values were maintained at $7-8$ and the temperatures at $24-26^{\circ} \mathrm{C}$. Nutrition was given every 5 days in the form of a mixture of TSP 15 ppm, Urea 70 ppm, and $\mathrm{NaHCO}_{3} 1 \mathrm{~g} /$ $\mathrm{L}$, in order to maintain the growth of Spirulina sp. The OD was measured using a spectrophotometer (OPTIMA SP-300) to determine cell concentrations in the Spirulina sp. For 30 days wavelengths at $680 \mathrm{~nm}$ were used to observe the presence of chlorophyll- $\alpha$. Increasing chlorophyll- $\alpha$ levels indicated that the Spirulina sp. was growing.

\subsection{Preparation of microplastics}

Microplastics used in this study were PE obtained from unused white plastic bags, and PP was provided by AQUA and designed as the packaging of mineral water. $\mathrm{PE}$ and PP were cut to around $1 \mathrm{~mm}^{2}$ in size. Afterwards, the microplastics were washed with ethanol and dried at room temperature for $24 \mathrm{hrs}$. They were then weighed carefully to $500 \mathrm{mg}$ and mixed into the bioreactor glasses already containing $2 \mathrm{~L}$ of Spirulina sp. culture. Aerators on the glass jars were used for the stirring process.

\subsection{Harvesting of Spirulina sp.}

To separate biomass and filtrate, a stainless steel screen wire mesh with a size of 40 microns was used. The microplastics were previously filtered out with a Whatman filter in order to avoid the mixing of Spirulina sp. and wet biomass. Wet biomass Spirulina sp. was subsequently dried in an oven at $30-35^{\circ} \mathrm{C}$.

\subsection{FTIR analysis}

An FTIR analysis was done to evaluate the effect of microplastic on organic elements with changes in organic functional groups. Measurements of chemical structures of the biomass were made at a wavelength range of $400-4,000 \mathrm{~cm}^{-1}$. 


\section{Results and discussion}

3.1 The influence of microplastics on the growth of Spirulina sp.

The results of the OD measurements are depicted in Figure 1. All three variables have experienced an increase in OD. On day 15, the OD in variable 1 saw a spike up to 0.772 . Meanwhile, variable 2 had a similar spike on day 21 up to 0.762 . Lastly, variable 3 experienced a spike on day 22 up to 0.779 . On the last day (day 30), variable 1 had reached OD of 0.994 . The OD in variable 2, however, remained lower and reached 0.912 on the last day, followed by variable 3 which reached an OD of 0.886 . This is in line with research conducted by Cunha et al. (2019), who demonstrated that microalgae contaminated with microplastic showed a decrease of up to $42 \%$ in the number of cells. From Figure 1, the growth rate of Spirulina sp. can be calculated with the following formula:

$$
\mu=\frac{\ln O D_{2}-\ln O D_{1}}{t_{2}-t_{1}}
$$

Where $\mu=$ growth rate $\left(\right.$ day $\left.^{-1}\right), \mathrm{OD}=$ Optical density at $680 \mathrm{~nm}$ and $\mathrm{t}=$ time (day)

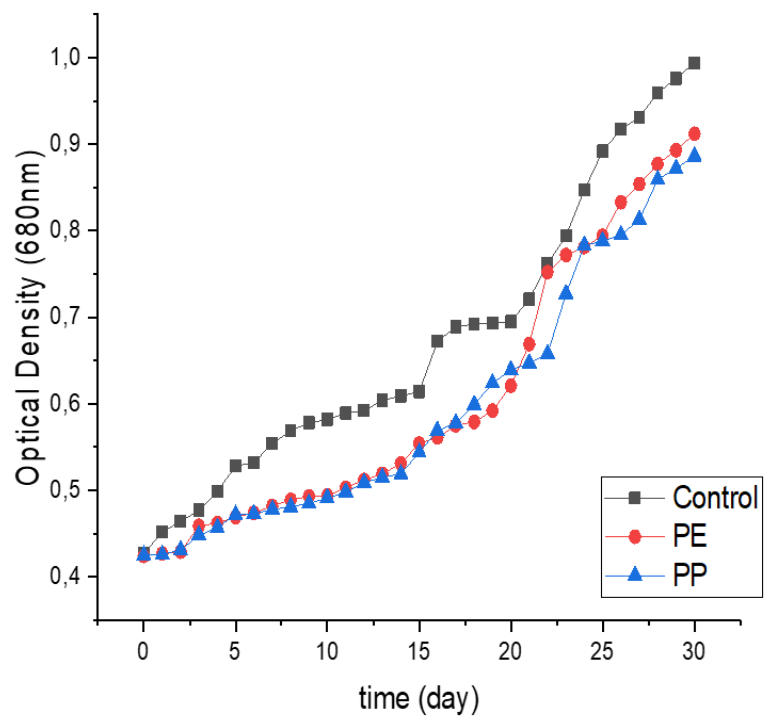

Figure 1. Microalgae growth of Spirulina $\mathrm{sp}$ for all three variables

Table 1 shows the growth rate of Spirulina sp. during the 30 days study of the three variables. The growth rate of variable 1 (control) was higher than with variables 2 and 3 . This is due to microplastics inhibiting the distribution of light and air and thus the process of photosynthesis on the surface of the cultivation area in Spirulina sp. (Hadiyanto et al., 2012; Sjollema et al., 2016). This is in line with Bhattacharya et al. (2010), who added microplastics $20 \mathrm{~nm}$ in size to the cultures of Chlorella and Scenedesmus and showed that there too, algae inhibited the process of photosynthesis due to the blockage of light and air.
Table 1. The growth rates of Spirulina sp for all three variables

\begin{tabular}{lcc}
\hline & System & Grow rate $(\mu)$ \\
\hline \multirow{3}{*}{ Fresh water } & Variable 1 & $0.229 /$ day \\
& Variable 2 & $0.208 /$ day \\
& Variable 3 & $0.189 /$ day \\
\hline
\end{tabular}

On the other hand, the presence of PE and PP microplastics also had positive effects. We saw a higher growth rate in Spirulina sp. that received PE and PP microplastics treatment than in Spirulina sp. without treatment. This seems to support the assessment that Spirulina sp. is able to utilize microplastics as a carbon source.

\subsection{FTIR analysis and the changes in polysaccharide} functional groups in Spirulina sp.

Negi et al. (2011) showed that polymers consisting of double bonds (such as PE) and triple bonds (such as PP) can be identified at wavelengths of 330 to $2,150 \mathrm{~cm}^{-}$ 1. The results of the FTIR analysis on variables 1, 2 and 3 are depicted in Figure 2. The FTIR analysis showed that variables 2 had a loss of polysaccharides at wavelengths $875.45 \mathrm{~cm}^{-1}$. This is due to PE having double bonds and degrading as much as twice as fast as PP. On the other hand, PP has a longer triplicate in aggregation, which causes an interaction between PP microplastic and Spirulina sp. to increase. This results in increased EPS production by Spirulina sp., but excessive EPS production can have a toxic effect. Sheng et al. (2010) explained that EPS from microalgae can absorb metals and organic compounds such as proteins and polysaccharides. The loss of two peaks indicates the presence of polysaccharides at wavelengths $1,245.67 \mathrm{~cm}^{-}$

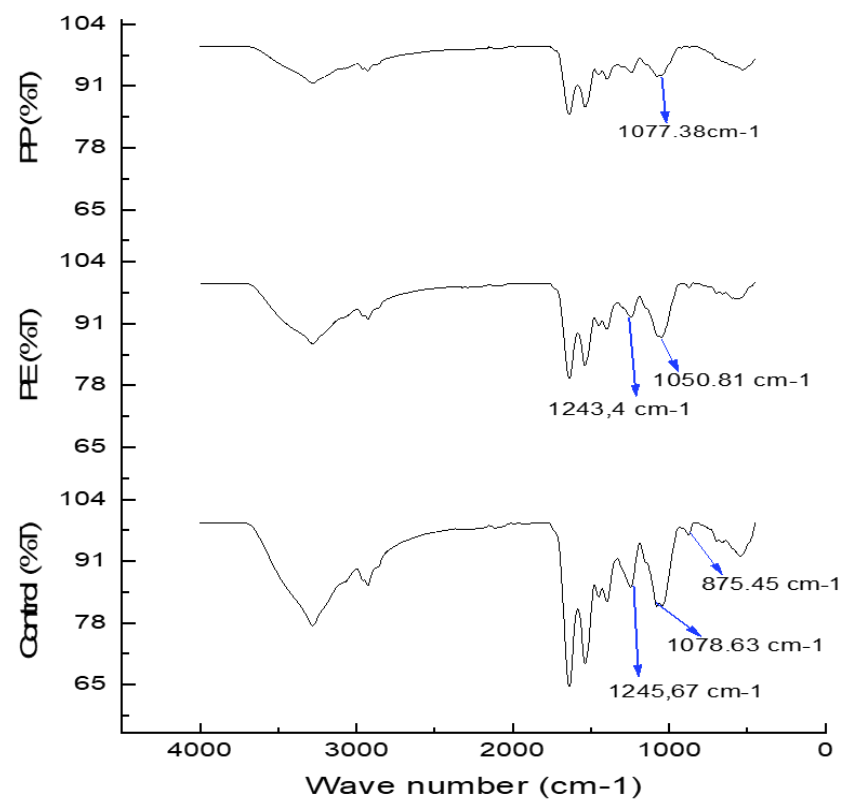

Figure 2. FTIR analysis results of Spirulina sp for all three variables 
Table 2. Results of FTIR analysis results on Spirulina sp for all three variables, showing the presence of polysaccharides

\begin{tabular}{cccccc}
\hline \multicolumn{2}{c}{ Variable 1 } & \multicolumn{2}{c}{ Variable 2 } & \multicolumn{2}{c}{ Variable 3 } \\
\hline polysaccharides & $\% \mathrm{~T}$ & polysaccharides & $\% \mathrm{~T}$ & polysaccharides & $\% \mathrm{~T}$ \\
\hline $1,245.67$ & 85.58 & $1,243.40$ & 92.37 & n.d & n.d \\
$1,078.63$ & 81.48 & $1,050.81$ & 88.19 & $1,077.38$ & 93 \\
875.45 & 96.52 & n.d & n.d & n.d & n.d \\
\hline
\end{tabular}

${ }^{1}$ and $875.45 \mathrm{~cm}^{-1}$.

The increase of $\% \mathrm{~T}$ can be seen in Table 2, showing that $\% \mathrm{~T} \mathrm{PP}>\% \mathrm{~T} \mathrm{PE}>\% \mathrm{~T}$. The greater the value of $\% \mathrm{~T}$, the lower the productivity of the resulting polysaccharides. The results of this study indicate that the presence of microplastics has a significant impact on the growth and quality of Spirulina sp. produced, especially in polysaccharide content.

\section{Conclusion}

The presence of PE and PP plastics showed a strong influence on the growth of Spirulina sp. The increased growth rate of Spirulina sp. due to added microplastics is not proportional to the increased quality of the produced biomass. Organic functional groups contained in biomass are indicators of the quality of Spirulina sp. The longer the interaction time between Spirulina sp. and plastic, the further the PE and PP plastics were degraded which caused the loss of some functional groups in the dry biomass of Spirulina sp. This is most notable in the polysaccharide group, an important component in Spirulina sp. The interaction between plastic and microalgae pro-vides phenomena that need to be further studied to devise a solution for handling the abundance of plastic waste in aquatic systems and the protection of the health of aquatic organisms.

\section{Conflict of interest}

The authors declare no conflict of interest.

\section{Acknowledgement}

The authors greatly appreciate the Biomass and Renewable Energy Group (C BIORE), Chemical Engineering Department, Diponegoro University for providing a fund to carry out this research.

\section{References}

Andrady, A.L. (2011). Microplastics in the marine environment. Marine Pollution Bulletin. Elsevier Ltd, 62(8), 1596-1605. https://doi.org/10.1016/ j.marpolbul.2011.05.030

Arutchelvi, J., Sudhakar, M., Arkatkar, A., Doble, M., Bhaduri, S. and Uppara, P.V. (2008). Biodegradation of polyethylene and polypropylene. Indian Journal of Biotechnology, 7(1), 9-22.
Bazaka, K., Crawford, R.J., Nazarenko, E.L. and Ivanova, E.P. (2011). Bacterial extracellular polysaccharides. In Linke, D. and Goldman, A. (Eds.) Advances in Experimental Medicine and Biology. Vol. 715, p. 213-226. The Netherlands, Dordrecht: Springer. https://doi.org/10.1007/978-94007-0940-9_13

Bergami, E., Pugnalini, S., Vannuccini, M. L., Manfra, L., Faleri, C., Savorelli, F., Dawson, K.A. and Corsi, I. (2017). Long-term toxicity of surface-charged polystyrene nanoplastics to marine planktonic species Dunaliella tertiolecta and Artemia franciscana. Aquatic Toxicology, 189, 159-169. https://doi.org/10.1016/j.aquatox.2017.06.008

Besseling, E., Foekema, E.M., Van Franeker, J.A., Leopold, M.F., Kühn, S., Bravo Rebolledo, E.L., Heße, E., Mielke, L., IJzer, J., Kamminga, P. and Koelmans, A.A. (2015). Microplastic in a macro filter feeder: Humpback whale Megaptera novaeangliae. Marine Pollution Bulletin, 95(1), 248 -252 .

j.marpolbul.2015.04.007

https://doi.org/10.1016/

Bhattacharya, P., Lin, S., Turner, J.P. and Chun Ke, P. (2010). Physical adsorption of charged plastic nanoparticles affects algal photosynthesis. Journal of Physical Chemistry C, 114(39), 16556-16561. https://doi.org/10.1021/jp1054759

Campanale, C., Massarelli, C., Savino, I., Locaputo, V. and Uricchio, V.F. (2020). A detailed review study on potential effects of microplastics and additives of concern on human health. International Journal of Environmental Research and Public Health, 2020, 17(4), 1212. https://doi.org/10.3390/ ijerph17041212.

Chentir, I., Hamdi, M., Doumandji, A., HadjSadok, A., Ouada, H. Ben, Nasri, M. and Jridi, M. (2017) Enhancement of extracellular polymeric substances (EPS) production in Spirulina (Arthrospira sp.) by two-step cultivation process and partial characterization of their polysaccharidic moiety. International Journal of Biological Macromolecules, 105(Part 2), 1412-1420. https://doi.org/10.1016/ j.ijbiomac.2017.07.009

Costa, A.M., Bueno, K.T.L., Rosa, A.P.C. and Costa, J.A.V. (2019). The antioxidant activity of nanoemulsions based on lipids and peptides from Spirulina sp. LEB18. LWT, 99, 173-178. https:// 
doi.org/10.1016/j.lwt.2018.09.069

Cunha, C., Faria, M., Nogueira, N., Ferreira, A. and Cordeiro, N. (2019). Marine vs freshwater microalgae exopolymers as biosolutions to microplastics pollution. Environmental Pollution, 249, 372-380. https://doi.org/10.1016/ j.envpol.2019.03.046

Dmytryk, A., Saeid, A. and Chojnacka, K. (2014). Biosorption of microelements by spirulina: Towards technology of mineral feed supplements. Scientific World Journal, 2014, 356328. https:// doi.org/10.1155/2014/356328

Farrell, P. and Nelson, K. (2013). Trophic level transfer of microplastic: Mytilus edulis (L.) to Carcinus maenas (L.). Environmental Pollution, 177, 1-3. https://doi.org/10.1016/j.envpol.2013.01.046

$\mathrm{Gu}$, J.D. (2003). Microbiological deterioration and degradation of synthetic polymeric materials: Recent research advances. International Biodeterioration and Biodegradation, 52(2), 69-91. https:// doi.org/10.1016/S0964-8305(02)00177-4

Hadiyanto, Widayat and Kumoro, A.C. (2012). Potency of microalgae as biodiesel source in Indonesia. International Journal of Renewable Energy Development, 1(1), 23-27. https://doi.org/10.14710/ ijred.1.1.23-27

Khoironi, A., Anggoro, S. and Sudarno. (2019). Evaluation of the interaction among microalgae Spirulina sp, plastics Polyethylene terephthalate and Polypropylene in freshwater environment. Journal of Ecological Engineering, 20(6), 161-173. https:// doi.org/10.12911/22998993/108637

Lagarde, F., Olivier, O., Zanella, M., Daniel, P., Hiard, S. and Caruso, A. (2016). Microplastic interactions with freshwater microalgae: Hetero-aggregation and changes in plastic density appear strongly dependent on polymer type. Environmental Pollution, 215, 331 -339. https://doi.org/10.1016/j.envpol.2016.05.006

Long, M., Moriceau, B., Gallinari, M., Lambert, C., Huvet, A., Raffray, J. and Soudant, P. (2015). Interactions between microplastics and phytoplankton aggregates: Impact on their respective fates. Marine Chemistry, 175, 39-46. https:// doi.org/10.1016/j.marchem.2015.04.003

Negi, H., Gupta, S., Zaidi, M.G.H. and Goel, R. (2011). Studies on biodegradation of LDPE film in the presence of potential bacterial consortia enriched soil. Biologija, 57(4), 141-147. https:// doi.org/10.6001/biologija.v57i4.1925.

Rummel, C.D., Jahnke, A., Gorokhova, E., Kuh-nel, D. and Jansen, M.S. (2017). Impacts of biofilm formation on the fate and potential effects of mi- croplastic in the aquatic environment. Environmental Science and Technology Letters, 4(7), 258-267. https://doi.org/10.1021/acs.estlett.7b00164

Setälä, O., Fleming-Lehtinen, V. and Lehtiniemi, M. (2014). Ingestion and transfer of microplastics in the planktonic food web. Environmental Pollution, 185, 77-83. https://doi.org/10.1016/j.envpol.2013.10.013

Sheng, G.P., Yu, H.Q. and Li, X. Y. (2010). Extracellular polymeric substances (EPS) of microbial aggregates in biological wastewater treatment systems: A review. Biotechnology Advances, 28(6), 882-894. https://doi.org/10.1016/ j.biotechadv.2010.08.001

Sjollema, S.B., Redondo-Hasselerharm, P., Leslie, H.A., Kraak, M.H.S. and Vethaak, A.D. (2016). Do plastic particles affect microalgal photosynthesis and growth?. Aquatic Toxicology, 170, 259-261. https:// doi.org/10.1016/j.aquatox.2015.12.002

Van Cauwenberghe, L. and Janssen, C.R. (2014). Microplastics in bivalves cultured for human consumption. Environmental Pollution, 193, 65-70. https://doi.org/10.1016/j.envpol.2014.06.010 